\title{
Continuing Medical Education Program in the Journal of Hospital Medicine
}

Thomas E. Baudendistel, MD, FACP ${ }^{1}$ CME Editor

Christine Lu-Emerson, mo ${ }^{1}$ David Likosky, $\mathrm{mD}^{2,3}$

Alpesh Amin, MD, MBA, FACP ${ }^{4}$ David Tirschwell, MD, Msc ${ }^{1,5}$

\author{
${ }^{1}$ Department of Neurology, School of Medicine, University of Washington, Seattle, Washington. \\ ${ }^{2}$ Department of Medicine, Hopitalist Program, Stroke Program, Evergreen Hospital Medical \\ Center, Kirkland, Washington. \\ ${ }^{3}$ Clinical Faculty, Department of Neurology, School of Medicine, University of Washington, Seattle, \\ Washington. \\ ${ }^{4}$ Department of Medicine, Hospitalist Program, University of California, Irvine, California. \\ ${ }^{5}$ University of Washington (UW) Medicine Stroke Center, Harborview Medical Center, Seattle, \\ Washington.
}

Disclosures: David Likosky and Alpesh Amin performed research and contributed to a supplement that was supported by Boehringer Ingelheim Pharmaceuticals, Inc.

Alpesh Amin also discloses a research/speaker's bureau relationship with sanofi aventis..
If you wish to receive credit for this activity, which begins on the next page, please refer to the website: www. blackwellpublishing.com/cme.

\section{Accreditation and Designation Statement}

Blackwell Futura Media Services designates this educational activity for a 1 AMA PRA Category 1 Credit. ${ }^{T M}$ Physicians should only claim credit commensurate with the extent of their participation in the activity.

Blackwell Futura Media Services is accredited by the Accreditation Council for Continuing Medical Education to provide continuing medical education for physicians.

\section{Educational Objectives}

Continuous participation in the Journal of Hospital Medicine CME program will enable learners to be better able to:

- Interpret clinical guidelines and their applications for higher quality and more efficient care for all hospitalized patients.

- Describe the standard of care for common illnesses and conditions treated in the hospital; such as pneumonia, COPD exacerbation, acute coronary syndrome, HF exacerbation, glycemic control, venous thromboembolic disease, stroke, etc.

- Discuss evidence-based recommendations involving transitions of care, including the hospital discharge process.

- Gain insights into the roles of hospitalists as medical educators, researchers, medical ethicists, palliative care providers, and hospital-based geriatricians.
- Incorporate best practices for hospitalist administration, including quality improvement, patient safety, practice management, leadership, and demonstrating hospitalist value.

- Identify evidence-based best practices and trends for both adult and pediatric hospital medicine.

\section{Instructions on Receiving Credit}

For information on applicability and acceptance of continuing medical education credit for this activity, please consult your professional licensing board.

This activity is designed to be completed within the time designated on the title page; physicians should claim only those credits that reflect the time actually spent in the activity. To successfully earn credit, participants must complete the activity during the valid credit period that is noted on the title page.

Follow these steps to earn credit:

- Log on to www.blackwellpublishing.com/cme.

- Read the target audience, learning objectives, and author disclosures.

- Read the article in print or online format.

- Reflect on the article.

- Access the CME Exam, and choose the best answer to each question.

- Complete the required evaluation component of the activity. 